\title{
Internationalization of the Practice in Education Degree: Students' Intercultural Experiences in the Teaching and Learning Process at Saharawi Refugee Camps
}

\author{
Inmaculada Gómez Hurtado ${ }^{1}$, Coronel, J. $\mathrm{M}^{1}$, Carrasco, M. J ${ }^{1}$, \& Correa, R. I \\ ${ }^{1}$ Department of Education, Universitiy of Huelva, Huelva, Spain \\ Correspondece: Inmaculada Gómez Hurtado, Department of Education, Universitiy of Huelva, Campus del \\ Carmen, Avenue Tres de Marzo, s/n, 21007, Huelva, Spain. Tel: 34-959-219-231. E-mail: \\ inmaculada.gomez@dedu.uhu.es
}

Received: November 12, 2012

Accepted: January 21, $2013 \quad$ Online Published: February 22, 2013

doi:10.5539/jel.v2n1p253

URL: http://dx.doi.org/10.5539/jel.v2n1p253

\begin{abstract}
Internationalization has become a key theme and widespread phenomenon in higher education. In this context, the inclusion of an international, intercultural and/or global dimension into the curriculum and teaching and learning process appears to be a substantive element in the academic sphere. This paper describes an initiative that was developed in a School of Education of small University related to how a group of teachers and student teachers attempted to include an international dimension into its teaching and learning process. The experience is developed in the schools of Refugee Camps. In conclusion, we discuss about the benefits of international experience in developing a intercultural attitude that is both sensitive to, and appreciative of, cultural diversity. The experience recognised a valuable opportunity for higher education to play a pivotal role in fostering intercultural understanding.
\end{abstract}

Keywords: internationalisation of teaching and learning process, intercultural interactions, international cooperation in higher education, globalization and international higher education

\section{Introduction}

One dimension nowadays considered more important, complex and confusing in higher education is the international dimension. Interest in internationalization as a key theme and widespread phenomenon has increased drastically since the 1990s (Albatch \& Knight, 2007; Kreber, 2009). Nowadays, scholars analysing a substantial quantitative growth in the number of analyses on internationalization of higher education (Kehm \& Teichler, 2007) and they tend to share the view that internationalization opens up more desirable opportunities than it produces dangers (Knight, 2004; Stromquist, 2007; Teichler, 2004). In any case, reflecting on what internationalization means cannot be separated from critically engaging with the question of what the purposes and goals of higher education should be, within specific programs and across programs, and the role of teachers, students, administrators and the institutions as a whole in contributing to these purposes.

While much has been written about internationalization at sector and policy levels (see, for example, the Bologna Declaration, 1999; Brown, 2000, De Witt, 1999; Altbach, 2003; Qiang, 2003), only a limited amount has been written recently about its implications for the core higher education activities of teaching and learning (Ryan, 2000; Wisker, 2000). However, any definition of internationalization must make clear and explicit reference to the centrality of the teaching and learning experience; otherwise, if this is seen as being subsumed (or tacitly understood) under the strategic and policy imperatives, there is a danger that it will be lost in the discourse, and therefore paid insufficient attention to. Both teachers and students are directly involved and affected by conditions in an increasingly international environment, and we need to clearly identify the ways in which this happens. In arguing that internationalization in higher education cannot refer to policy alone, it becomes a logical step to argue that curriculum design and course development, in its broadest sense (including course content but also teaching and learning styles and strategies) needs explicit attention at all levels of the internationalization process.

We suggest, therefore, that to have real meaning in higher education, any definition of internationalization needs to incorporate explicit reference to teaching and learning, and therefore, to be at the heart of any policy making 
and strategy development (Leask, 2001; Luxon \& Peelob, 2009). Moreover, in this process we must include a significant touch of international / intercultural dimension into the teaching, research and institutional issues that are held in higher education, and must be made explicit and brought to the forefront of the discussion.

Curriculum refers to all the activities, experiences, and learning opportunities (that is, the entire teaching and learning environment) that students, academics, administrators, and support staff are part of. Internationalizing the curriculum involves educating for world-mindedness. Educating for world-mindedness comprises of more than selecting appropriate contents and pedagogies to ensure that these address the needs of international students; it also implies awareness raising among all students and staff about issues of diversity and intercultural sensitivity and the full integration of these considerations into the curriculum. In this way, the rationale underlying this internationalization of curricula is principally social/cultural and academic but also critical with approaches that treat internationalization as the addition of multicultural elements to a Western curriculum (Jones, 2000; Kreber, 2009; Noddings, 2005).

Internationalization in higher education is not achieved with the inclusion of international theoretical contents, but rather with understanding through interaction, empathy, relationships with others and listening to others. Considering that one of the basic objectives of higher education is to promote the overall development of the student in a competitive society, it is essential that our students have to acquire the multicultural ability and attitude to serve to the cultural diversity that is present in sociaty. Moreover, it's necessary to include the other in our realm of understanding for everyday interactions and is even greater in professional contexts. The problem with such a multicultural attitude is embedded in our limited ability as individual human beings to grasp the other in terms different to our own, and as "cultural beings" to extend our cultural horizons of understanding beyond the boundaries shaped by our own contextually situated life stories. Understanding the other person's culture demands an extra effort on the part of the knower, which is not without risk (Turniansky, et. al., 2009; Vainio-Mattila, 2009).

The increasingly important international dimension in education calls for awareness of the world's complexity and interdependence, communication skills across cultures, and appreciation of cultural differences as resources (Hobbs \& Chernotsky, 2007). Understanding connections between theory and praxis impacts academic pursuits (Galura et. al., 2004). On internationalization there is still a gap in such literature, although work evaluating specific programs (e.g., Odgers \& Giroux, 2006) or aspects of programs such as the nature of international volunteerism (Tiessen \& Heron, 2007), have started to emerge.

Vainio-Mattila (2009, p.100), considers it a discussion about the possibility of embedding it in a critical pedagogy that seeks to guide the student to understand herself or himself as an active agent in society as well as to identify and create conditions for a more just society - in other words, anchoring the process of internationalization in the core educational mission of higher education rather than presenting it as a delivery mechanism. It's a "pedagogical revolution" that challenges the institutionalized systems of domination. Education is a vehicle for transmission myths and power relations that benefit the dominant social groups. The symbolic power and control translate into principles of communication through the discursive practices of visible and invisible pedagogies (Bernstein, 1990).This concept is relevant if internationalization is to be understood as a forum of such change. Curriculum development, in general, and internationalization of curriculum in particular, present us with critical opportunities to create the "new kind of education".

The internationalization develops ethical commitment to allow students to examine their implicit and explicit beliefs and develop a sense of responsibility and civic engagement (Kreber, 2009). Against an ethos of competition, this experience is based on an ethos of cooperation to serve a more profound educational purpose: Higher education plays a key role in promoting intercultural understanding, greater attention to the needy through international cooperation.

According to Hooks (2003, p. 41), teachers who practice democratic education believe that learning never limited to what was done in class. Thus, university teaching is permanently connected with the world and real problems.

The student mobility allows students to transfer to a different environment, but this is not enough. It is helping to understand the connections between the local environment in which they live, and the global environment. To increase the impact of the internationalization of the curriculum in the educational experience, Vainio-Mattila (2009) believes that we should pay less attention to the quantitative data about the international education (e.g., number of students from other countries, exchange programmes, etc.) and cater more to the creation of learning communities involving different people in different contexts .

Cushner and Mahon (2002) argue that teachers do not have much experience in intercultural matters. This 
situation is very similar in most teacher education' students. Pre-service and in service teachers have been widely socialized in the classroom but they haven't overall knowledge. By having few opportunities to develop international understanding alternative possibilities are not appropriate. Therefore, it's necessary to help students develop intercultural skills (Teekens, 2003).

This experience draws on Freirean pedagogy (Freire, 1995) to frame learning in such a way that our students have a chance of not only becoming good global citizens, but agents of change actively pursuing more equal and just relationships. The essence of critical pedagogy is the world's transformation from action based on a committed and socially relevant knowledge (Giroux and McLaren, 1998). In this study, we describe how intercultural approaches address issues such as social justice, equity, human rights, and related social and economic issues; address critical global environmental issues and includes topics on ethical issues in globalization. Equally, it includes an investigation of professional practices in other cultures and an exploration of how knowledge may be constructed differently from culture to culture in the subject area concerned.

\section{The Experience}

Research on the international dimensions of higher education has substantially expanded in recent years. For more than a decade, this topic has been a thematic area drawing from a broad range of disciplines and research domains. Modes of inquiry did not change substantially over time. Kem \& Teichler (2007) note studies based on literature review, analysis of documents, interviews, and questionnaire surveys. Some studies are based on a broad range of modes of inquiry, whereas others are dominated by a single way of collecting information. These authors notice a substantial number of studies that might be called case studies covering various programmes, institutions, actors, and countries (e.g., Echvin and Ray, 2002; Thune \& Welle-Strand, 2005).

This experience provides a case study of how a group of teachers and students from a small University attempts to include an international dimension into its teaching and learning process. According to Stromquist (2007), the naturalistic method of the case study enables the researcher to present the points of view of the social actors involved, and to link these perceptions to their particular locations in academic units. Case studies provide an in-depth look into phenomena that might easily be missed when using questionnaires that cover a large number of universities but minimize the particular context and location in which they operate. So, in the study conducted by Deardorff (2004) to determine a definition and appropriate assessment method of intercultural competence as a greed on by a panel of internationally known intercultural scholars, case studies and interviews received the strongest agreement $(90 \%)$ followed by analysis of narratives diaries, self-report instruments, observation by others/host culture, and judgment by self and others (all at $85 \%$ agreement).

Most of the work is related to the experience of students participating in an international programme of study within a University (Campbell \& Li, 2008; Devos, 2003; Turner, 2009). However, two aspects are distinct and unique to this experience. Firstly, it is a lived experience of college students that takes place off campus, in a radically different cultural, geographic and social context. It is an experience that describes the inclusion into the life of the University of students from other cultures or countries. Secondly, a distinctive feature of this experience emerges 'from below', that is, from the students themselves. It did not emerge from the academic structure, nor is it the result of institutional policies. Neither has it come from teachers or lecturers; it is an initiative of the students themselves.

\subsection{Contexts and Participants}

In 1975, the decolonization process and the subsequent invasion by Morocco forced the Saharawi population to flee through the Western Sahara desert, eventually settling in an area near Tindouf in southern Algeria. There they built a series of camps, four in all, the Aium, comprising Auser, Smara and Dakhla. The Aium's political and social organization is structured like the organization of a state. This organization and the associated work have been, and continue to be, what has allowed the Saharawi to survive in such a severe a situation. There is a president, a National Assembly and various ministries. In each camp or province, the highest authority is the Governor. Each province (wilaya) is divided into 6 or 7 villages (daira), each with its Mayor and Aldermen. Each daira has five departments that organize social and political life and is divided into four districts with neighborhood councils. Each wilaya has a hospital and a special school. In each daira, there is a clinic and school. There are also two boarding schools. Political and administrative life is headquartered in Rabbouni. The General Hospital and other infrastructure services and training are also in Rabbouni.

The situation of the population is extreme. They live in a sedentary form in camps desert itself, surviving on international support that reaches them irregularly and in insufficient quantities.

Despite the appearance of structure and availability of services, this is a world apart, totally different from what 
we know. However, despite these difficulties, the people have something priceless: they apply themselves to a challenge and this yields greater results than might be apparent when considering the limited infrastructure of their society. There is a strong family structure where respect for elders and for women is crucial. The Saharawi people believe in their cause and continue to struggle politically to retrieve what belongs to them: the Western Sahara.

The University of Huelva is a young and small university founded in 1993. Located in the southwestern region of Andalucía (Spain), it has about 11,000 students served by 700 teachers. It offers nearly 50 degrees at undergraduate and Master levels. The School of Education has 3,000 students and offers degrees in Teacher Education, Social Education, Masters in Psychology and several educational subjects.

The experience, developed over 6 years (2006-2011), has engaged a group of 4 teachers from the Department of Education and a total of 46 students from the Teacher Education (Special Education, Primary Education and Language Education), Social Education and Psychology degree courses. In this research, participate two teacher and twenty six students.

\subsection{Process}

This experience arises in 2005/2006 academic year when a group of students from the Special Education Teacher undergraduate course, particularly sensitive to socio-educational reality in disadvantaged contexts, made a request to the different authorities of university to support a visit to in the Saharawi refugee camps in Tindouf (Algeria). The main objective of the visit was to diagnose the situation of schools in the camps serving children with special educational needs (educational resources and equipament, number and disabilities type of pupils and training needs of teachers). A subsequent visit was planned to implement a plan for concrete action at these locations.

In the next academic years saw a further increase in the number of students wanting to participate in the experience, and begin the Educational Intervention Project for Education in the Saharawi Camps. During the years of this Project we saw that it was appropriate for them to participate as students of that partipate of Primary Education, Special Education, Social Education, Psychology and Education Psychology Degree. Normally, 10 students travel to the Sahara each year. Our objectives was to extend the training of the teachers in the camps, attend to the special needs of Saharawi children in the Special School, teach Spanish in Mainstreams School. The aim was to encourage the development of stable institutional links between the camps and the Faculty of Education at the University of Huelva. These objetives were given the opportunity to show solidarity with Saharawi people.

We stayed in two camps. We had judged these camps, Ausser and Dakhla, to have the greatest need (schools located in dessert context attended great number of pupils with disabilities). The students worked during the day with education program for attending the different special needs of Saharawi children in special school, and in mainstream schools teach the second language that is Spanish. For this practice, the students are divided in small groups, depending the particular degree they were studying. In the evening, they engaged in the leisure activities. At night we shared living space with the families in the haimas. Every student helped each other to do the activities.

On this trip, the faculty identified the need to bring to our own country the principals of the special education schools. In particular individuals were brought to our university to receive training, as some of them did not have specific or formal training. Of course, teachers have no training. In 2010, we obtained their passports and the saharawi schools principal made a stay at our university. In this stay, they went to classes related to Special Education and visited Primary and Special schools to learn educational strategies for attending to students with special needs.

In 2010 and 2011, we expanded our objectives and we decided to train to the participant students in the project. Thus, for several weeks before the stay in the camps, the teachers involved in this project taught to the students how is the educational and social intervention in the camps, explained the context and developed an intervention project and the material needed to carry it out.

In addition, in preparation for when they stay with us, the students carry out advocacy and fundraising to enable them to bring school supplies and medicines to the Sahara.

\subsection{Data and Analysis}

The study reported here was designed to assess the nature of the international student teaching experience and its impact on professional and personal development. In their own words, student teachers who have had the courage to embark on such an experience give voice to the contributions made to their own personal and 
professional development. Students are encouraged to stretch beyond their traditional "comfort zone". The projects that students worked on were directly related to the development needs that the Saharawi community had identified. Data had been collected through in-depth interviews with seventeen students (from a total of twenty-six) and with two university teachers who participated in the experience.

Two in-depth interviews with the university teachers were conducted with a focus on examining and exploring their perspectives as teachers and their own assessment of the experience. It included the following aspects: the extent of integration of the experience into the curriculum and connections with internships to highlight methodological issues in the experience content addressed, process evaluation and changes, assessment of their own role as teachers in the experience, difficulties and problems encountered, the degree of institutional support, and demands and future prospects.

Thus, in relation to the students, a total of fourteen struture interviews were conducted. The interviews addressed issues such as the role in this project, the stay in the camps, their experience, their training, integration of culture, their practice in other context, etc.

In relation to the process of analysis, the use of narrative and discourse analysis was continual throughout the research process (Cortazzi, 1993). Inductively, we paid close attention to the discovery of patterns and themes by means of identification, coding, and categorizing the various elements, thereby establishing the relationships between the elements with the intent of reducing the large volume of collected data (Strauss and Corbin, 1990).

\section{Results}

With respect to the University teachers, we conclude that the whole experience is seen as an excellent opportunity for training students. It was not merely engaging in "fair tourism", but was a means to make contact with a different reality and to develop concrete action through projects grounded in reality. Although the experience is not reflected in the official, course syllabus it has not been necessary so far to incorporate it as such. However, on returning from visiting the camps, the students' work continues and connections with the specific subjects, the official program and with actual practice are maintained.

Regarding the teachers' own role in the management and coordination of activities, in particular during the stay, a) they play the role of representatives of the University, b) they make decisions about the work to be done, c) they are central to the planning of the work process. But mostly they work in the particular task of processing and adapting the draft prepared by the students, to make it a concrete reality. The projects developed require adaptation and selection of priority issues in terms of the demands of time and resources in the context of the reality of daily life in the camps. One teacher commented in the following way:

"Keep in mind that time, the pace of life in the camps is very distinct and different from ours. This conditions development work absolutely". (Teacher-1)

Concerning the assessment of the experience, teachers mainly emphasize the importance of experience and of generating in the students a commitment to "do something". They acknowledge that the impact of experience leads them, once they return to the University, to maintain a high level of critical awareness and commitment.

As for changes, learning obtained during these four years leads them to make an effort to prioritize and work more in depth on specific aspects: "The first two years we went to every camp and worked at all of them. The third and fourth year, we visited just two. We think that next time we will only work in a single camp, but with more dedication and in greater depth" (Teacher-2).

The main difficulties have been those related to illnesses suffered by the students and the necessary care of unwell students and the numerous constraints imposed by the context and the limited resources available.

With regard to institutional support, the faculty said that, over the years, this has been increased. For example, a plane ticket for students is now funded $100 \%$ by the University. Moreover, the Department of Education and School of Education allocated funds to purchase two sets of school supplies.

With regard to needs, teachers' perceptions could be grouped around the following issues:

a) The need to involve more lecturers in visits to the camps. It is essential to open the experience to other colleagues for the survival of this initiative.

b) It is necessary to overcome the bureaucratic obstacles that prevent teachers from the camps from coming to Spain and the University for training.

c) The opportunity to work collaboratively with other universities through the creation of the inter-university network can provide an impetus for the future creation of a School of Education in the Saharawi territories. 
d) The experience needs further consolidation at the corporate level and should have a prominent place within international policies of the University.

e) Students who participate in the experience have an important role and have crucial tasks to perform. They must transmit sensitization and awareness in the rest of the students. This process must continue.

In relation to students, the results of this study show that learning is constructed by the learners through collaboration with others within a specific cultural context.

The factors that motivate students to take the decision to become involved in the pedagogic experience include a desire to experience reality in a different educative situation as well as a desire work with and to help others, all this in a distinctly different context and under a strong commitment to solidarity. Similarly, feedback and reports by peers who have already participated in the experience have served to convince them of the benefits of going. One student commented:

"The reasons that led me to participate in this project was a wish to live a new experience in an unfamiliar but interesting context, both personally and professionally. I thought that my training would be useful and that it would be a fruitful journey to experience another culture and to have that personal experience. Despite the benefits, I felt a little "fear" not knowing the reality that awaited me, but once there, this feeling disappears and you are filled with hope and involvement with the Saharawi people".

With regard to the involvement in projects, students play a very active role in developing and implementing various educational and leisure projects and are welcomed as part of the joint working team.

Situations or issues highlighted by the students during the stay affect various aspects of everyday activity, in general, and intercultural sensitivity, in particular. Thus we have, for example, the treatment, kindness, honesty, mutual support and caring and generous behavior both amongst themselves and with people coming from outside, or the fact that educational work is conducted without support or resources and with only minimal infrastructure. Students also highlighted the role of the talks and the development of everyday life, having to share your stay with families. The feeling of being welcomed and of the hospitality shown by the Saharawi families is strongly felt by the students. For example, students' comments such as: "The smiles of the children in schools and outside them, the ability of Saharawi teachers to listen, the ideological image of humility and simplicity of the Saharawi people, the feeling of calm transmitted by the sand dunes, the silence and darkness of night", all give an idea of how the experience has shaped the lives of students.

In terms of understanding and integration into a different culture, and despite the limited time period, the students seem to have shown "cultural sensitivity". Previous research has identified intercultural sensitivity as central to the role of education and improving relationships cross culturally (Hammer, Bennett, \& Wiseman, 2003).

One meaningful outcome of internationalization efforts at postsecondary institutions is the development of competent 'intercultural' students (Nieto \& Zöller, 2010). Yet few universities address the development of students' intercultural competence as an anticipated outcome of internationalization, that is, an outcome in which the concept of "intercultural competence" is specifically defined. This lack of specificity in defining intercultural competence is presumably due to the difficulty of identifying the specific components of this complex concept (Deardorff, 2006). The concept is defined by Hammer et al., (2003, p. 422), as "the ability to discriminate and experience relevant cultural differences." Deardoff $(2004$, p. 194) defines intercultural sensitivity as "the ability to communicate effectively and appropriately in intercultural situations based on one's intercultural knowledge, skills, and attitudes." Chen and Starosta have defined intercultural sensitivity as the affective aspect of intercultural communication where the individuals have an "active desire to motivate themselves to understand, appreciate, and accept differences among cultures" (Peng, 2006, p. 39). Intercultural sensitivity is viewed as an "attitudinal forerunner to successful intercultural encounters and a predictor of cultural competence" (Altshuler, Sussman, \& Kachur, 2003, p. 388). For Hammer et al., (2003), the greater the intercultural sensitivity, is the greater the potential for exercising cultural awareness.

Of the specific components of intercultural competence noted, many of them address an individual's personal attributes, such as curiosity, general openness, and respect for other cultures. Participants in the study described in this essay recognized the importance of personal readiness for the understanding of, and integration within, a different culture. Despite the limited time available for adaptation and integration, the process has been positive. And certainly, living with families in their homes has contributed to that positive outcome.

Research in the field of cultural learning suggests that as a result of significant experience in a culture other than one's own, there is an increase in 'world-mindedness' and in ethnocentrism and a reduction in the use of negative 
stereotypes, as well as greater sophistication in one's thinking about others (Cushner \& Brislin, 1996).

Students developing the skills that enable an individual to live and work effectively among individuals from cultures other than their own require significant, long-term, direct personal interaction with people and contexts different from those in which one is most familiar.

This experience has meant a lot to students both personally and professionally. From the standpoint of training and professional, it has helped bring new ways to meet the challenge and new ways to work and to appreciate pupils' desires and aspirations rather than focusing on the availability or rather, the lack of resources when working. From the standpoint of education, participating students have recognized the importance of family in the educational process and have developed a deep respect for people of different cultures. One student commented: "From my point of view, knowledge of other realities and cultures and respect for them very important values that a teacher must be prepared to do some work to transmit to others."

Another student expresses: "For myself, I learnt not to cling to fixed concepts, to closed ideas, above all when it involves an unfamiliar situation, not to allow myself to be carried along by impressions, to believe in myself and in those ideas that I believe and that give me inspiration, how to work in a group, with a well-formed team, to share living-space and to enjoy sharing a home with people who may be very different from me in many ways, to be a part of and truly to experience another person's situation and to criticize myself and to value everything that has allowed me my own life".

But it appears that the impact of the experience on a personal level has been the most significant for students. This experience has made them mature as individuals, more inclined to question the prevailing values in our society and to value seemingly simple and less important things. One student particularly valued "personal enrichment that [the experience] has brought me. I do not need anything more to my background, growing as a person is worth more than any specific knowledge that I might acquire".

As for the actions taken after the experience, students have taken part in various activities and initiatives: information campaigns, photo exhibitions, fundraising campaigns, sales materials and articles, participating in associations and for a concerning the Saharawi people, as this blog of cooperation and volunteerism describes (Note 1).

With regard to areas for improvement, students especially highlighted the need to extend the length of stay in the camps, the need for a greater fit between expectations and subsequent reality, the possibility of sending more material or the desirability of more information of all kinds about the Sahara and its people. From the point of view of actions, students recognize the desirability of working in greater over a smaller number of camps. The requirement to have more continuity and involvement is also noted.

The students' assessment of the experience is highly positive. "magic", "unforgettable", "unique", "incredible", "the most important in my life," "one of the best I could have," are some expressions collected during the interviews.

Students expressed the need for the University to continue to support this initiative and welcomed the work undertaken by their faculty from the point of view of support and contribution to their academic and personal. Moreover, they also expressed the hope that someday the Saharawi Democratic Republic may become an internationally recognized reality.

Finally, this last section will emphasize that a result of this experience has been the creation of a network that currently involves 4 Universities working together in a cooperative education project to be developed continuously for 3 months in the Saharawi refugee camps.

\section{Conclusion}

This experience, aimed at incorporating an international and intercultural dimension into the curriculum has led to significant learning and change in participants, both at the personal and the professional level. The contact and interaction with another culture and a very different reality has produced positive effects on behavior as well as the development of a multicultural attitude that is both sensitive to, and appreciative of, cultural diversity.

The effects of the experience are projected into the reality of participants' lives, reflected in their actions and subsequent commitment and in changes in how they deal with professional and personal situations.

This experience has provided opportunities for staff and students to develop "global citizenship" competencies, including an understanding of global issues as well as ways to actively engage in addressing these issues. Experiences such as these are generally more effective in preparing teachers for culturally diverse classrooms and produce an increased cultural knowledge, a broadened global perspective, and an increased belief in the 
value of multicultural education through interaction with children, other professionals, and adults from different cultural backgrounds.

Analyzing this particular initiative in internationalization in terms of its underlying motivation, one might say that the main driver was a willingness to offer voluntary services where they were needed, to use the existing partnership to offer richer learning opportunities within a broad range of disciplines, but also to learn about other cultures.

In short, to meet the needs of the 21 st century, schools must successfully teach an increasing number of students from diverse backgrounds while preparing them for a much more complex, interdependent world that may be unfamiliar to most teachers themselves. Consequently, the nature of teacher preparation and the settings in which students must learn to teach must undergo substantial change.

Internationalization will not be truly successful or sustainable unless it becomes fully integrated into all the activities and policies of the institution. The teaching and learning experience, as reflected in curriculum development and course design, is an essential part of the internationalization process, and this needs to be articulated in all discussions of policy.

\section{References}

Altbach, P. G., \& Knight, J. (2007). The Internationalization of Higher Education: Motivations and Realities. Journal of Studies in International Education, 11(3-4), 290-305. http://dx.doi.org/10.1177/1028315307303542

Albatch, P. G. (2003). Foreign Study: Changing Patterns and Competitive Challenges. International Higher Education, 33, 2-3.

Altshuler, L., Sussman, N., \& Kachur, E. (2003). Assessing changes in intercultural Sensitivity among physician trainees using the intercultural development inventory. International Journal of Intercultural Relations, 27, 387-401. http://dx.doi.org/10.1016/S0147-1767(03)00029-4

Bernstein, B. (1990). Poder, educación y conciencia. Barcelona: El Roure.

Bologna Declaration. (1999). Joint declaration of the European Ministers of Education. Retrieved August 15, 2005, from http://www.cepes.ro/information_services/sources/on_line/bologna.htm

Brown, M. (2000). Do we need a strategic international development function in universities? In G. Wisker (Ed.), Good practice working with international students (pp. 7-20). Birmingham, UK: Staff \& Educational Development Association.

Cortazzi, M. (1993). Narrative Analysis. Londres: The Falmer Press.

Cushner, K., \& Brislin, R. (1996). Intercultural interactions: A practical guide (2nd ed.). Thousand Oaks, CA: Sage.

Cushner, K., \& Mahon, J. (2002). Overseas Student Teaching: Affecting Personal, Professional, and Global Competencies in an Age of Globalization. Journal of Studies in International Education, 6(1), 44-58. http://dx.doi.org/10.1177/1028315302006001004

Deardorff, D. K. (2006). Identification and Assessment of Intercultural Competence as a Student Outcome of Internationalization. Journal of Studies in International Education, 10(3), 241-266. http://dx.doi.org/10.1177/1028315306287002

Deardorff, D. K. (2004). The identification and assessment of intercultural competente as a student outcome of international education at institutions of higher education in the United States. Unpublished dissertation, North Carolina State University, Raleigh.

De Witt, H. (1999). Changing rationales for the internationalization of higher education. International Higher

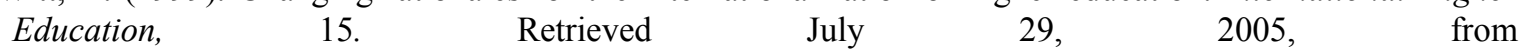
http://www.bc.edu/bc_org/avp/soe/cihe/newsletter/News15/text1.html

Freire, P. (1995). Pedagogía del oprimido. Madrid: S.XXI.

Galura, J. A., Pasque, P.A., Schoen, D., \& Howard, J. (2004). Engaging the Whole of Service-Learning, Diversity, and Learning Communities. Ann Arbor, MI: The OCSL Press at the University of Michigan.

Giroux, H., \& McLaren, P. (1998). Sociedad, cultura y educación. Madrid: Miño.

Hammer, M., Bennet, M., \& Wiseman, R. (2003). Measuring intercultural sensitivity: The intercultural development inventory. International Journal of Intercultural Relations, 27(4), 421-443. 
http://dx.doi.org/10.1016/S0147-1767(03)00032-4

Hobbs, H., \& Chernotsky, H. (2007). Preparing Students for Global Citizenship. Paper presented at the American Political Science Association Teaching and Learning Conference, Charlotte, NC, Feb. 9-11, 2007. Retrieved July 22, 2007, from http://www.apsanet.org/tlc2007/TLC07HobbsChernotsky.pdf

Hooks, B. (2003). Teaching Community: A Pedagogy of Hope. London/New York: Routledge.

Jones, P. (2000). Globalization and internationalism: democratic prospects for World education. In N. Stromquist \& K. Monkman (Eds.), Globalization and Education: Integration and Contestation Across Cultures (pp. 27-42). Boulder: Rowman \& Littlefield.

Kehm, B. M., \& Teichler, U. (2007). Research on Internationalisation in Higher Education. Journal of Studies in International Education, 11(3-4), 260-273. http://dx.doi.org/10.1177/1028315307303534

Knight, J. (2004). Internationalization Remodeled: Definition, Approaches, and Rationales. Journal of Studies in International Education, 8(1), 5-31. http://dx.doi.org/10.1177/1028315303260832

Kreber, C. (2009). Different Perspectives on Internationalization in Higher Education. New Directions for Teaching and Learning, 118, 1-14. http://dx.doi.org/10.1002/tl.348

Leask, B. (2001). Bridging the Gap: Internationalizing University Curricula. Journal of Studies in International Education, 5(2), 100-115. http://dx.doi.org/10.1177/102831530152002

Luxon, T., \& Peelob, M. (2009). Internationalisation: Its implications for curriculum design and course development in UK higher education. Innovations in Education and Teaching Internacional, 46(1), 51-60. http://dx.doi.org/10.1080/14703290802646172

Nieto, C., \& Zoller Booth, M. (2010). Cultural Competence Its Influence on the Teaching and Learning of International Students. Journal of Studies in International Education, 14(4), 406-425.

Noddings, N. (2005) Educating Citizens for Global Awareness. New York: Teachers College Press.

Odgers, T., \& Giroux, I. (2006). Internationalizing Faculty: A Phased Approach to Transforming Curriculum Design and Instruction. Paper Presented at the York University Annual International Conference on Internationalizing Canada's Universities.

Qiang, Z. (2003). Internationalization of Higher Education: Towards a Conceptual Framework. Policy Futures in Education, 1(2), 248-270. http://dx.doi.org/10.2304/pfie.2003.1.2.5

Ryan, J. (2000). A guide to teaching international students. Oxford, UK: Oxford Brookes University, Oxford Centre for Staff \& Learning Development.

Strauss, A., \& Corbin, J. (1990). Basics of Qualitative Research. Newbury Park: Sage Pub.

Stromquist, N. P. (2007). Internationalization as a response to globalization: Radical shifts in university environments. Higher Education, 53(1), 81-105. http://dx.doi.org/10.1007/s10734-005-1975-5

Teekens, H. (2003). The Requirement to Develop Specific Skills for Teaching in an Intercultural Setting. Journal of Studies in International Education, 7(1), 108-119. http://dx.doi.org/10.1177/1028315302250192

Teichler, U. (2004). The changing debate on internationalisation of higher education. Higher Education, 48(1), 5-26. http://dx.doi.org/10.1023/B:HIGH.0000033771.69078.41

Tiessen, R., \& Heron, B. (2007). Creating Global Citizens: Impact of Volunteer and Work Abroad Programs. Ottawa, Ontario: International Development Research Centre, Canada.

Turniansky, B., Tuval, S., Mansur, R., Barak, J., \& Gidron, A. (2009). From the Inside Out: Learning to Understand and Appreciate Multiple Voices Through Telling Identities. New Directions for Teaching and Learning, 118, 39-47. http://dx.doi.org/10.1002/t1.351

Vainio-Mattila, A. (2009). Internationalizing Curriculum: A New Kind of Education? New Directions for Teaching and Learning, 118, 95-103. http://dx.doi.org/10.1002/t1.356

Wisker, G. (2000). Good practice working with international students. Birmingham, UK: Staff \& Educational Development Association.

\section{Note}

Note 1. http://www.nohaymurosparalaconciencia.blogspot.com 